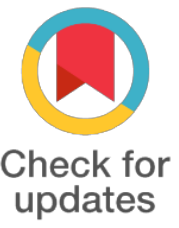

*For correspondence:

huynhvanman@yahoo.com

Competing interests: The authors declare that no competing interests exist.

Received: 2017-06-30 Accepted: 2017-07-25

Published: 2017-09-05

Copyright The Author(s) 2017. This article is published with open access by BioMedPress (BMP).

This article is distributed under the terms of the Creative Commons Attribution License (CC-BY 4.0) which permits any use, distribution, and reproduction in any medium, provided the original author(s) and the source are credited.

\section{Evaluation of HLA-identical sibling allogenic peripheral blood stem cell transplantation for acute myelogenous leukemia at BTH, Vietnam}

\author{
Thu Nguyen Hanh, Huynh Van Man, Huynh Duc Vinh Phu, Phu Chi Dung, \\ Nguyen Tan Binh \\ Blood Transfusion Hospital, Ho Chi Minh, Vietnam
}

\section{Abstract}

Background: the purposes of this study were to assess the efficacy of HLA-identical sibling allogenic peripheral blood stem cell transplantation in the treatment for acute myelogenous leukemia (AML) at Blood transfusion and hematology hospital at Ho Chi Minh city.

Methods: retrospective study, case series.

Results: from June 2005 to September 2016, there were 47 AML patients included 24 males and 23 females, with median age was 36 years old. Engraftment was achieved in 47 patients (100\%). The median number of transfused $\mathrm{CD}_{34}+$ cells was $7.5 \times 106 / \mathrm{kg}$. The median time for neutrophil engraftment and platelet engraftment were $11 \pm 2.8$ days and $12.5 \pm 10.1$ days respectively. Oral mucositis occurred in 38 patients $(80.9 \%)$, febrile neutropenia in 42 patients $(89.4 \%)$, acute graft-versus-host disease (aGvHD) in 14 patients $(29.8 \%)$, chronic graft-versus-host disease (cGvHD) in 10 patients (21.3\%), and VOD in 6 patients (12.8\%). Transplant-related mortality (TRM) was 4 patients (8.5\%). Median follow-up time was 52.26 months. Patients remained alive were 27 (57.4\%). The 5-year overall survival (OS) and disease-free survival (DFS) were $55 \%$ and $54 \%$ respectively.

Conclusion: HLA-identical sibling allogeneic blood stem cell transplantation can reconstruct hematopoiesis quickly and is a favorable therapeutic method for AML patients. Further development and improvement of hematopoietic stem cell transplantation techniques along with graduated and individualized therapy are expected to provide better outcomes and improved quality of life for AML patients.

\section{Keywords}

AML, HLA-Identical sibling

Funding

References 